\title{
Development of a chemiluminescence enzyme immunoassay for the detection of aflatoxin $\mathbf{M}_{1}$
}

Yifan Lang ${ }^{1, a}$, Zhenzhen Chen ${ }^{1, b}$, Lixin Zhu ${ }^{1, c}$, Renrong Liu* ${ }^{*}$ Xuemei Qiu ${ }^{1}$, Kaihong $\mathrm{Li}^{1}$, Fanfan Yang ${ }^{1}$, $\mathrm{Na} \mathrm{Hu}^{1}$

School of Life Science, Jiangxi Science \& Technology Normal University, Jiangxi, Nanchang, 330013, China

a yifan052913@163.com, ${ }^{\mathrm{b}}$ 827342314@qq.com, ' zhulixin007@163.com

*corresponding author: lilirenrong@hotmail.com

Keywords: aflatoxin $M_{1}$; chemiluminescence enzyme immunoassay

Abstract. An indirect competitive chemiluminescence enzyme immunoassay (CLEIA) for detecting aflatoxin $\mathrm{M}_{1}\left(\mathrm{AFM}_{1}\right)$ was developed. In the experimentation, antigen coated concentration, antibody dilution proportion, $\mathrm{pH}$ value and ionic concentration of the buffer were optimized to obtain the best reaction condition. Finally, the $50 \%$ inhibitory concentration $\left(\mathrm{IC}_{50}\right)$ of the optimized CLEIA is $0.11 \mathrm{ng} / \mathrm{mL}$ for skimmed milk powder, and the recovery ranged from $77.98 \%$ to $104.39 \%$.

\section{Introduction}

Aflatoxins are highly toxic mycotoxins which is formed when ruminants ingest feed contaminated with aflatoxin $\mathrm{B}_{1}[1]$. Currently available research results demonstrate that aflatoxin $\mathrm{M}_{1}$ can also be present in a wide range of milk-derived products or products containing milk, such as cheese, yogurt, cream and chocolate[2,3].

Several analytical methods are currently available for aflatoxin $\mathrm{M}_{1}$ determination, including high-performance liquid chromatography associated with fluorescence or mass spectrometric detection [4,5]. Enzyme-linked immunosorbent (ELISA) methods have also been described [6] and are widely employed as screening methods in routine analysis, mainly because of their simplicity and rapidity.

To effectively monitor the occurrence of aflatoxin $\mathrm{M}_{1}$ in food at low contamination levels, sensitive, reliable and simple analytical methods are required. This work describes the establishment of a sensitive quantitative CLEIA (chemiluminescence enzyme immunoassay). CLEIA is a combination of chemiluminescence (CL) and enzyme immunoassay, it has combined advantages of the high sensitivity of CL and the high specificity of immunoassay[7].

\section{Materials and methods}

Reagents and instrument: Mouse anti-aflatoxin $\mathrm{M}_{1}$ monoclonal antibody was obtained from our own laboratory. Horseradish peroxidase-labeled goat anti-mouse IgG-HRP were purchased from sigma (St. Louis, MO, USA). Chemiluminescence substrate was purchased from Helisence (Shanghai, China). Phosphate-buffered saline (PBS), PBS with 0.05\% Tween-20 (PBST), Well wash versa (Thermo scientific, USA), 96-well white polystyrene plates (Costar, USA), 5804R High-speed Refrigerated Centrifuge (Eppendorf, Germany).

Determination of AFM $_{1}$ by CLEIA: CLEIA was carried out using 96-wells white polystyrene plates. The plates were coated by adding into each well $120 \mu \mathrm{L}$ of $\mathrm{AFM}_{1}$-BSA antigen dissolved in PBS, and incubated at $37^{\circ} \mathrm{C}$ lucifuge moisturize for coating $2.5 \mathrm{~h}$, then washed with PBST and blocked by adding $330 \mu \mathrm{L}$ per well of $5 \%$ skim milk powder, which incubated at $37^{\circ} \mathrm{C}$ for $3.5 \mathrm{~h}$. After washing 3 times with PBST, $100 \mu \mathrm{L}$ of horseradish peroxidase (HRP)-conjugated anti-antibody were added to each well incubating condition as the former except for time $(45 \mathrm{~min})$. Finally, $100 \mu \mathrm{L}$ substrate solution prepared freshly was added into each well. The chemiluminescence intensity was 
monitored on a Luminoskan Ascent (Thermo, USA). In the experiment, the $\mathrm{RLU}_{\max } / \mathrm{IC}_{50}$ ratio was used as a parameter to judge the impact of factors.

\section{Sample Preparation}

The $1 \mathrm{~g}$ of skimmed milk powder sample was suspended in $10 \mathrm{~mL}$ of $50{ }^{\circ} \mathrm{C}$ distilled water. $20 \mathrm{ml}$ acetonitrile was added to extraction the spiked aflatoxin $\mathrm{M}_{1}$, and the mixture was shaken on a rotary shaker for $10 \mathrm{~min}$. The extracting solution was centrifuged at $6000 \mathrm{r} / \mathrm{min}$ for $10 \mathrm{~min}$ at $4^{\circ} \mathrm{C}$. The supernatant was obtained and heated in water bath to evaporating off the acetonitrile. Then the sample was diluted with water.

\section{Result and discussion}

\section{Optimized concentrations of coating antigen}

The concentrations of the coating antigen was optimized by the phalanx titration which the antigen coated concentration range from $0.25 \mu \mathrm{g} / \mathrm{mL}$ to $4 \mu \mathrm{g} / \mathrm{mL}$, and the antibody dilution proportion range from 1:80000 to 1:5120000. The result was showed in Fig.1, AFM ABSA $_{1}$ conjugate concentration of $0.5 \mu \mathrm{g} / \mathrm{mL}$ is optimum for coating the plates.

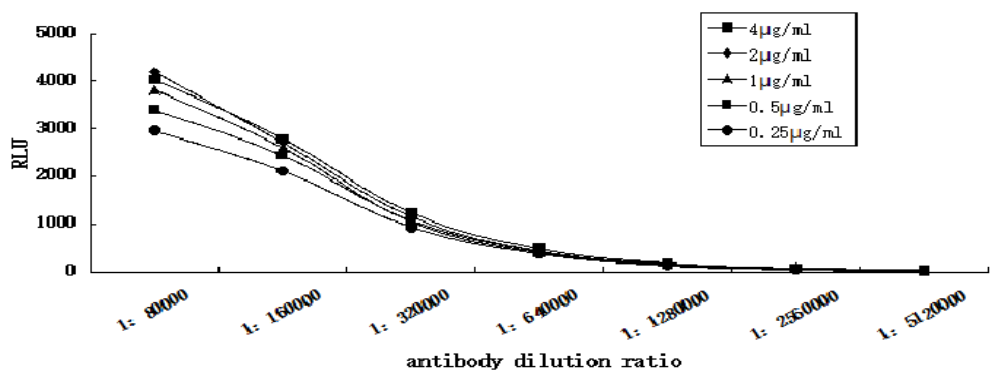

Fig.1. The RLU effect of varied concentrations of coating antigen

\section{Optimized the antibody dilution proportion}

The antibody dilution proportion was optimized by the indirect competitive. The certified reference material was diluted with purified water to $0.02 \mathrm{ng} / \mathrm{mL}, 0.05 \mathrm{ng} / \mathrm{mL}, 0.2 \mathrm{ng} / \mathrm{mL}, 1 \mathrm{ng} / \mathrm{mL}$, $2.5 \mathrm{ng} / \mathrm{mL}$ and doubling dilution for antibody concentration range from 1:320000 to 1:2560000. From the Fig.2, the best dilution proportion of antibody is 1:320000.

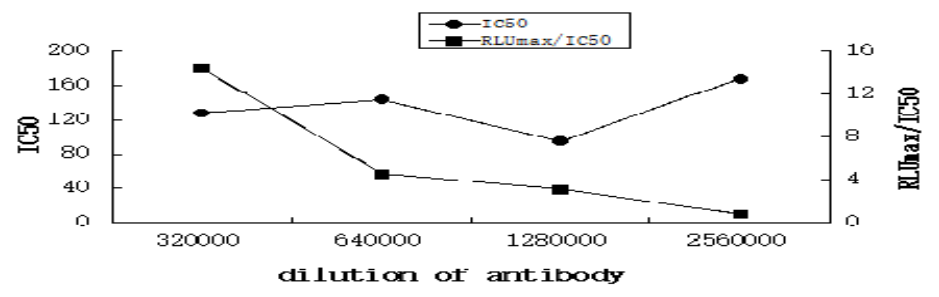

Fig.2. The effect of antibody dilution proportion

\section{Optimized the ionic strength and the $\mathrm{pH}$ value of the buffer}

In this step, the ionic strength of the buffer ranges from $0 \mathrm{~mol} / \mathrm{mL}$ to $2 \mathrm{~mol} / \mathrm{mL}$, the $\mathrm{pH}$ value of the buffer ranges from 5.5 to 9.0. The result showed that the $\mathrm{pH}$ value of buffer showed in Fig.3 (b) is ruleless to luminescence value. So the optimum condition of ionic strength and $\mathrm{pH}$ value is 1mol/L、7.0, respectively in the Fig.3(a) and Fig.3 (b).

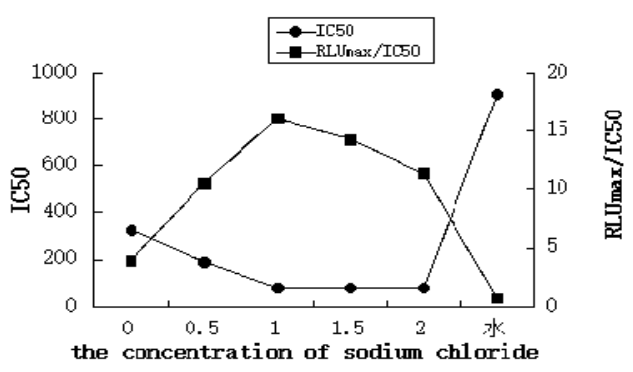

Fig.3(a). The effect of sodium chloride

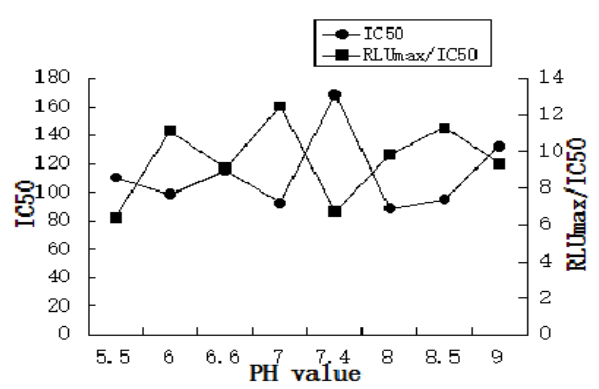

Fig.3(b). The effect of the $\mathrm{pH}$ value 


\section{Optimized the concentration of organic solvents}

The certified reference material of $\mathrm{AFM}_{1}$ was diluted different concentrations of methanol and the purified water. From the Fig.4, the best result is with purified water dilution.

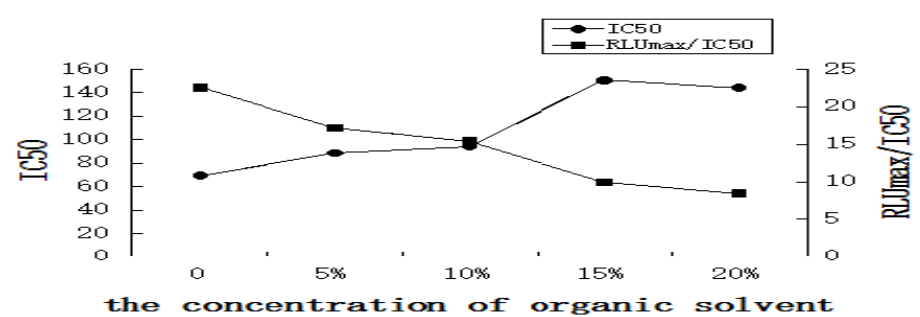

\section{Establishment of the Standard Curve}

Fig.4. The effect of the concentration of organic solvent

In the assay, the later step experiment condition used the result of the former. According to the optimized parameters, the standard curve is shown in Fig.5. The horizontal coordinate in the Fig.5 was obtained by enlarging 1000 times of original concentration then calculating the logarithm. The $\mathrm{IC}_{50}$ was $0.11 \mathrm{ng} / \mathrm{mL}$. The linear working range determined was $0.05-0.4 \mathrm{ng} / \mathrm{mL}$.

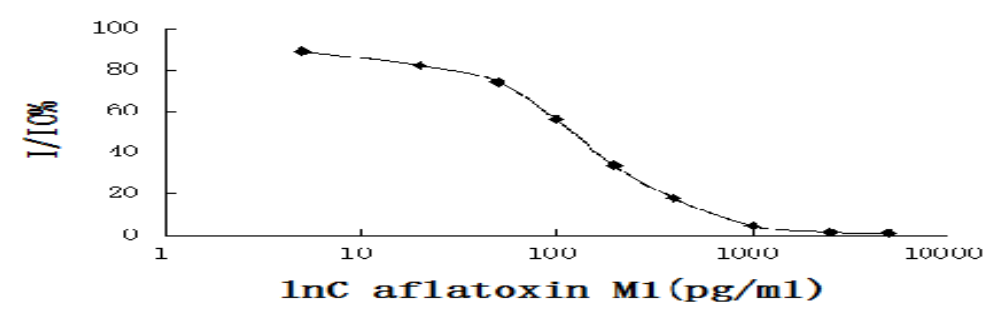

\section{Recovery Studies of Spiked Samples}

Fig.5. The inhibition curve of aflatoxin $\mathrm{M}_{1}$

In this procedure, we take action of diluting to eliminate the interference. The recovery ratio and SD value for spiked skimmed milk powder are listed in table 1.

The table 1 shows that the recovery ratio of the experiments are acceptable and the all SD values are lower than $10 \%$. It proves that the CLEIA method has a good precision.

Table 1 The recovery ratio and SD value for skimmed milk powder

\begin{tabular}{|c|c|c|}
\hline Adding standard & Recovery ratio & SD value \\
\hline $10 \mathrm{ng}$ & $93.48 \%$ & $2.53 \%$ \\
\hline $20 \mathrm{ng}$ & $104.39 \%$ & $8.94 \%$ \\
\hline $30 \mathrm{ng}$ & $77.98 \%$ & $2.55 \%$ \\
\hline
\end{tabular}

\section{Conclusion}

In the experiment, an action of diluting was exploited to eliminate the sample matrix interference. A sensitive and efficient CLEIA has been established to detect aflatoxin $\mathrm{M}_{1}$. This method was performed with wide linear range and low LOD for skimmed milk powder. The recoveries ranged from $77.98 \%$ to $104.39 \%$. The method has showed a good precision for aflatoxin $\mathrm{M}_{1}$ detection and it is suitable for detection of trace aflatoxin $\mathrm{M}_{1}$ in food.

\section{Acknowledgement}

This work was financially supported by grants from National Natural Science Foundation of China (No.81360429) and Natural Science Foundation of Jiangxi Province(No. 20122BAB214006, 20114BAB205039, KJLD14067). 


\section{Reference}

[1] MARIA MAGLIULO, MARA MIRASOLI, PATRIZIA SIMONI, et al. Development and Validation of an Ultrasensitive Chemiluminescent Enzyme Immunoassay for Aflatoxin $\mathrm{M}_{1}$ in Milk [J]. AGR FOOD CHEM, 2005,53(9): 3300-3305.

[2] A. Govaris, V. Roussi, P. A. Koidis, et al. Distribution and stability of aflatoxin $\mathrm{M}_{1}$ during production and storage of yoghurt [J]. Food Additives \& Contaminants, 2002:1043-1050.

[3] LAURA ANFOSSI, MARIANNA CALDERARA, CLAUDIO BAGGIANI, et al. Development and Application of Solvent-free Extraction for the Detection of Aflatoxin $\mathrm{M}_{1}$ in Dairy Products by Enzyme Immunoassay [J]. AGR FOOD CHEM, 2008, 56(6): 1852-1857.

[4] Joerg Stroka, Elke Anklam. New strategies for the screening and determination of a£atoxins and the detection of aflatoxin-producing moulds in food and feed[J]. trends in analytical chemistry, 2002,21(2).

[5]NOBUYUKI TAKEDA. Determination of aflatoxin $\mathrm{M}_{1}$ in milk by reversed-phase high-performance liquid chromatography [J]. Journal of Chromatography, 1983:484-488.

[6] Radoi A, Targa M, Prieto-Simon B, et al. Enzyme-Linked Immunosorbent Assay (ELISA) based on superparamagnetic nanoparticles for aflatoxin $\mathrm{M}_{1}$ detection [J]. TALANTA,2008,77(1):138-143.

[7] Ping Li, Yan Zang, Hongtao Lei, et al. Development of chemiluminescent enzyme immunoassay for the determination of aflatoxin $\mathrm{M}_{1}$ in milk products [J]. Food and Agricultural Immunology, 2015,157-69. 